Адрес статьи / To link this article: $\underline{\text { http://cat.ifmo.ru/ru/2016/v1-i1/61 }}$

\title{
Медиасреда: поле битвы или стихия взаимопонимания
}

\author{
Л.Ю. Яковлева \\ Санкт-Петербургский государственный университет, Россия \\ yakovleva.liubovegmail.com
}

\begin{abstract}
Аннотация. В рамках проблемы формирования «медиасреды» рассматриваются такие темы, как статус медиареальности, медиа как «архив эпохи», вопросы транспортной медиации, медиальность городского пространства, медиавойны и медиальность терроризма, соотношение нарратива, образа, телесности и медиа; особое внимание уделяется анализу последних разработок и инноваций в области компьютерных игр, их влиянию на формирование практик повседневности.
\end{abstract}

Ключевые слова: медиасреда; архив; медиареальность; медиавойна; медиасубъект; компьютерные игры; нарратив; телесность.

Конференция «Медиасреда: поле битвы или стихия взаимопонимания» проводилась в рамках Международного научно-культурного форума «Дни философии в Санкт-Петербурге-2015» при поддержке гранта Российского научного гуманитарного фонда (шифр 15-03-14108 «г»). На мероприятии присутствовали как постоянные участники, так и новые гости из различных городов России, Европы и других стран. Продолжая восьмилетнюю традицию, Центр медиафилософии под руководством Валерия Савчука принял более 60 докладчиков, привлек несколько десятков молодых слушателей, подтвердив тем самым востребованность и необходимость медиафилософского дискурса.

Открыл пленарное заседание руководитель конференции, профессор СанктПетербургского государственного университета Валерий Савчук, который посвятил свое выступление взаимодействию медиа и человека с помощью образа колонизации. Образ колонизации как проявления силы на определенной территории позволил объединить два важнейших блока конференции, а именно: темы медиавойны и проблем топологического дискурса в анализе медиальности. «Колонизацию медиа», как отметил профессор Савчук, «можно прочитать двояким образом»: при входе в медиа мы колонизируем ее, при ее входе в нас - она колонизирует нас. Такая двойственность возвращает нас к известному концепту Валерия Савчука «медиа внутри нас». Колонизация оказывается столь мгновенной и всеобъемлющей, что, входя в нас, она стирает все четкие оппозиции между «вне» и «внутри». Выступая в качестве участников медиальных сообществ, мы теряем не только свой собственный рассудок, но и тело, которое становится телом чужим, коллективным. Однако, несмотря на такой тотальный медиальный захват, как полагает Савчук, исследователь медиа исходит из необходимости обретения свободы: «...если мы найдем такую точку сборки, где мы зафиксируем себя в подлинности, и если мы примем эту точку как инстанцию для мысли, тогда мы действительно будем находиться экстерриториально, экс-статически по отношению к медиальной среде». 
Следующий доклад исследователя архивов Густава Шпета, профессора Татьяны Щедриной (Москва) осветил проблему Интернета как «архива эпохи». Расшифровывая заметки на полях того или иного автора, мы обращаемся к эпохе, к контексту, в котором жил автор. Для этого мы используем Интернет, который следует рассматривать не только как скопление ненужных смыслов, но и как собрание ценных текстов и образов. С одной стороны, этот медиальный, постоянно изменяющийся архив может предоставить нам такие ответы, сохранить такие следы, которые никогда не может нам дать архив физический. С другой стороны, он лишен «стилистики письма» - подлинных следов размышлений, почерка, перечеркнутого текста. Это порождает проблемы идентификации авторства и сохранения постоянно исчезающих следов в динамике современного «архива эпохи».

Не только Интернет, но и кинематограф может быть назван своего рода «архивом эпохи», требующим сохранения и интерпретации. Главный редактор киностудии им. М. Горького Андрей Апостолов (Москва) на примере фрагментов из кинолент «Падение Берлина» и «Клятва» (реж. М.Э. Чиаурели, 1946 г.) предложил интерпретацию образа Сталина как медиума. Если современники Сталина могли воспринимать его кинематографический образ как реальность, а Сталина как носителя истины, то задача докладчика состояла в прояснении статуса этого носителя. Сталин в отличие, например, от Ленина, был именно носителем, медиумом и буквально телесным воплощением ленинизма. Сталин, выступая в качестве молчаливого транслятора языка идеологии, репрезентировался как идеальный медиум, позволяющий разрешить все различия языков между людьми.

Куратор петербургского философского кафе Алла Митрофанова сконцентрировала внимание на проблеме медиарельности как особого объекта. Опираясь, прежде всего, на «новую метафизику объекта», развиваемую американским философом Грэмом Харманом, Алла Дориановна продемонстрировала необходимость переосмысления классического понятия объекта. Объект должен быть рассмотрен в качестве медиального: он связан с чувственностью воспринимающего (связь с субъектом), с категориальностью и каузальностью (связь с другими объектами). Объект становится «многослойным медиумом».

В следующей секции «Морфология медиасреды: стратегии ориентации» внимание участников было направлено на исследование различных аспектов топологии и ее трансформации в медиасреде.

Коллеги из Волгограда Андрей Кузнецов (к.соц.н., доц.) и Денис Сивков (к.ф.н., доц.) в своих выступлениях проблематизировали медиальность в контексте поворота к мобильности. Андрей Кузнецов обратился к теме транспорта как медиа: в соответствии с подходом Маклюэна, докладчик поставил вопрос о том, как транспорт трансформирует пространство и время. Кузнецов показал, что имеет значение не только изменение внешнего пространства города под влиянием изменяющихся транспортных сообщений, но и внутреннего пространства самого транспорта. На примере современных маршрутных такси он рассмотрел проблемы анонимности, персонификации, отчуждения и его возможного преодоления в отношении к пассажирам. Сами пассажиры выступили в качестве изменяемого, «форматируемого» материала при помощи транспортной медиации. Денис Сивков развил проблему неотчужденных отношений между людьми при помощи гаджетов и транспорта. Как транспорт, так и гаджеты глубоко вплетены во всевозможные практики нашей повседневности. Это позволяет увидеть социум не только как единство не сообщающихся монад, не только как молчаливую анонимность, но и как возможность для реального взаимодействия. Эту разобщенность и одновременное сближение людей, имеющих непосредственное отношение к проблемам морали, Сивков сформулировал в виде открытого вопроса-метафоры «Вместе или раздельно».

Особого внимания в анализе пространства заслуживает доклад «Медиальность инфраструктуры: топосы (не)видимого города» Дарьи Колесниковой (к.ф.н., зав. лаб. визуальной экологии, СПб). Она обратилась к проблеме репрезентации городского пространства Парижа, проанализировав его на основе проекта Бруно Латура «Париж: невидимый город». Цель его проекта заключалась в том, чтобы показать невидимость, невозможность прямой репрезентации города Парижа как целого. Для выявления пространственных, политических и социальных механизмов функционирования города, Латур создал особые контрольные центры «олигоптиконы». Олигоптиконы представляют собой небольшие локусы-сцены, в которых

International Culture \& Technology Studies, Vol. 1, No. 1 
участвуют актеры, и имеют ограниченный взгляд на сам город. В такой ограниченной оптике локусов-систем, состоящих из множества элементов, (на примере функционирования олигоптикона бюрократического пространства школы) человек обретает особую способность видения: через локальные, конкретные и ограниченные действия он получает доступ к работе всей системы. Метод, который осуществляет эту связь локального и целого, ограниченного и тотального, был назван Латуром «зуммирование». Таким образом, перенастраивая нашу способность видимого, философ позволяет пересмотреть наши возможности репрезентации видимого и невидимого, частного и тотального.

Последняя секция первой части конференции «Конституция медиасубъекта: сознание, желание, травма», среди участников которой были магистры и аспиранты, объединила в себе ряд таких острых проблем, как исчезновение другого из медиареальности, вопросы взаимодействия медиа и медицинского дискурса, трансформация отношения к смерти в медиапространстве, феномен прозрачности и его репрезентация в искусстве. Между докладами Кирилла Шерстобитова и Юрия Войнилова (Москва) возникла концептуальная параллель в контексте соотношения живого и мертвого, реального и виртуального. Они стремились показать, что реальность виртуального имеет независимый от человека статус. Вне зависимости от того, жив человек или мертв, «жизнь» его аккаунтов будет продолжаться, изменяя тем самым наше привычное разделение на живое и мертвое.

Второй день работы конференции начался секцией «Эффекты медиа: война, идеология, террор». В ее рамках докладчики затронули такие вопросы, как свобода и насилие, статус врага и жертвы, законы существования терроризма в медиальном пространстве, трансформация ведения войны в эпоху сетевых сообществ.

В своих докладах спикеры заострили внимание, прежде всего, на проблемах этики субъекта, существующего в медиареальности. Философы Наталья Жадунова и Екатерина Коваль (Саранск), Марина Корецкая и Елена Савенкова (Самара) признали, что медиаформат, в котором обитает современный человек, вынуждает каждого из нас принимать опосредованное участие в войне. Риторика этого формата была обозначена в качестве «риторики жертвы».

Первые докладчики попытались наметить перспективы сопротивления навязываемым нам образам войны в виде отказа от реакции на происходящие события. Отсутствие действия становится противодействием, нежеланием принимать участие в формировании решений относительно политических событий. Только так, полагают Н. Жадунова и Е. Коваль, мы можем говорить о сохранении моральных оснований.

В отличие от них М. Корецкая и Е. Савенкова видят проблему не столько в сохранении этической позиции, сколько в необходимости переосмысления границ этического дискурса в рамках медиавойн. Елена Савенкова озвучила тезис о смешении «этики и эстетики». Здесь уместно говорить об «этической ловушке», которая задается механизмами визуализации террора. Мы всякий раз уже вовлечены в эстетический процесс созерцания казни и других событий, завлечены в этику циническую, то есть этику «размытых границ», где нет четких позиций сопротивления или согласия. При этом в рамках биополитики, которой философ Марина Корецкая посвятила свое выступление, субъект обладает правом на свободное решение, на принятие самостоятельной позиции. На деле же все оборачивается прежней логикой суверена: мы охраняем вашу жизнь и ваши права лишь постольку, поскольку мы уже задействовали их в качестве ресурса для ведения войны в формате медиа.

Александр Секацкий (к.ф.н., доц., СПб.) изменил курс дискуссии о войне в медиа на проблему войны медиа. Он противопоставил агональным отношениям больших СМИ, их внутренней войне «откочевывающие» миры дружелюбных локальных сообществ. В отличие от постоянных соревнований медийных гигантов, с их подковерными играми и борьбой за признанность, разворачивается мир, где все это оказывается ненужным. Сообщества «кошколюбов» или кулинарных рецептов не заинтересованы в особой признанности, где достаточно лишь лайков или аплодисментов за оставленные там комментарии. Однако члены таких сообществ все же вынуждены иногда покидать свои медийные тела соцсетей и вступать в реальные контакты. В ответ на вынужденную двойственность такого существования Александр Куприянович предложил провокативную и одновременно циничную идею еще не раскрытого нами возможного мира: такого мира, который предлагал бы товарную форму зависти. Каждый,

Культура и технологии, Том 1, № 1 
кто испытывал бы потребность во «фрагменте» признанности, получал бы пакет зависти от других людей. Если можно купить завидующих вам людей, то купить можно абсолютно все. Так рождается сообщество, в котором не нужно знать потайные ходы к получению славы и признанности, не нужно вести медиавойны и добиваться авторства, но можно заказать себе пакет завистливых услуг, решив тем самым все проблемы. «Это потенциальная площадка для высадки сетевого народа», — заметил Секацкий.

Аналитики компьютерных игр в рамках секции «Компьютерные игры: от колонизации виртуальных миров к формированию повседневности», опираясь на последние нововведения разработчиков, представили наиболее значимые изменения в практиках, алгоритмах и структуре игры.

Проблема внутренних изменений компьютерных игр наиболее четко была сформулирована Маргаритой Скоморох (старший аналитик ЛИКИ, СПб) в ее докладе «Мазокор и хоррор: наследие Сада и Мазоха в компьютерных играх...»: «Из игры уходит игра». Данный тезис стал лейтмотивом таких докладов как «Newsgames: или игры, или новости» Андрея Муждабы (редактор gamestudies.ru) и «Просто классные предельно, чтобы сдвинуться по ним...» профессора из Лондона Метью Фюллера.

В своем докладе Маргарита Скоморох рассмотрела жанр мазокора как радикальной деструкции законов компьютерной игры. Мазокор представляет собой такую модель, в которой игроки выполняют ложные указания, монотонные, ни к чему не приводящие задачи, иногда предлагающие игроку убить себя. В таком случае остается испытывать удовольствие от неудовольствия, становясь мазохистом. Однако при более пристальном рассмотрении мазохизм мазокора оборачивается садизмом. Такие игры не оттягивают страдание как в эстетике Мазоха, но напротив, сгущают, интенсифицируют негативность восприятия. «Злые» игры, мучающие, уничтожающие геймеров - это симптом легкости прежних компьютерных игр, «игра умерла» заключает Скоморох.

Андрей Муждаба обратился к рассмотрению newsgames, которые так же, как и мазокор трансформируют законы функционирования компьютерных игр. На примере ряда игр аналитика Gamestudies Гонзало Фраски, докладчик представил возможность нефикциональных игр, в основе которых заложена особая «риторика неудач»: играя в новостные игры, мы никогда не сможем выиграть. Однако, в отличие от моделей мазокора, негативный опыт выступает не целью, a средством. С помощью newsgames, которые основаны на реальных событиях, связанных в основном с террористическими актами, игрок встает перед выбором: «или игры, или новости». Выбирая игру, мы отказываемся от реальности новостей, и склоняемся к альтернативным моделям, предлагаемым новостными играми.

Меттью Фюллер в своем выступлении, которое проходило по Skype, как и предыдущие докладчики сосредоточил внимание на смещении границ традиционных игр. Особый акцент профессор сделал на изменении структуры игровых практик: логика игры становится открытой, а взаимодействие большого количества участников позволяет приходить к решению задач различными способами.

В секции «Медиа как формат актуальной реальности: технология, нарратив, образ» особо следует отметить доклады аспиранта Ольги Мокшановой (СПб) и ученого секретаря центра медиафилософии Константина Очеретяного. Ольга Мокшанова проанализировала тесное переплетение медиального и биологического дискурсов: современная биология в своем подходе к исследованию жизни опирается на теорию информации, то есть «прочитывает» жизнь как письмо кода. Следовательно, мы имеем дело не с самой жизнью, но с ее закодированным следом, который не имеет реального референта. В таком случае расшифровка начертаний хромосом устраняет различие между медиумом живым и неживым, между медиальностью компьютерных машин и органических тел. Проблему форматирования тела и его взаимодействия с миром продолжил К. Очеретяный в докладе «Тело в формате медиа: реминисценция, репрезентация, актуализация». Представив ключевые моменты в генезисе соотношения тела и медиа от античности до современности, он выделил две противостоящие друг другу парадигмы: если до современности тело было основой, выражаемой при помощи знака и образа, то в XX веке тело полностью перешло в область воображаемого. Оно перестало быть источником и стало субстратом для медиальности. К. Очеретяный отметил вероятность того, что человек никогда

International Culture \& Technology Studies, Vol. 1, No. 1 
не имел доступа к непосредственной телесности, взаимодействуя лишь $\mathrm{c}$ eе культурно и технически отформатированной версией. Тем не менее, современная медиальность тела отличается от предыдущих эпох, она изменяет базовые параметры телесности и переучреждает ее встроенность в мир. Отсюда возникает необходимость дальнейшего исследования взаимодействия тела и медиа.

Докладчики Дарья Калинкина (асп., СПб) и Виктор Полиектов (маг., СПб) затронули проблемы нарциссизма и удовольствия в медиапространстве: было предложено рассматривать интерфейс соцсетей, формируемый в соответствии с нашими запросами, в качестве зеркала, образующего символический капитал субъекта. При этом, как полагает В. Полиектов, этот символический капитал потребляется в состоянии перманентной анестезии. Такая атрофия чувствительности требует радикальной трансформации при помощи катастроф, которые может организовывать клиническая психология при работе с нарциссическим сознанием, порожденным медиасредой. В завершающей части конференции в докладе «Мобильность и репрезентация пользователей в социальных сетях» Диана Сатыбалдина (маг., Екатеринбург) возобновила проблематику перемещений в медиапространстве, которые обсуждались в первой части конференции. Она указала на то, что наши перемещения и встречи по большей части имеют место лишь в виртуальном пространстве в формате подтверждений присутствия на тех или иных событиях. Реальное перемещение становится нарративом, рассказом о том, где я был. Отсюда следует, что методология, применяемая к анализу мобильности, может быть заимствована из нарратологии.

Подводя итог, следует отметить, что пространство конференции, несмотря на разнообразие ракурсов и подходов к анализу медиареальности, предстало скорее в качестве «стихии взаимопонимания», а не «поля битвы». Об этом свидетельствует само событие диалога, которое уже на протяжении восьми лет собирает не только философов, но и социологов, журналистов и других исследователей медиареальности.

\title{
The Media Environment: the Battlefield or the Element of Understanding
}

\author{
L. Yakovleva
}

Saint-Petersburg State University, Russia

\begin{abstract}
This article deals with scientific reports devoted to the actual questions of media philosophy. Within the problem of media environment, the article examines such topics as status of medea reality, media as archive, problems of transport mediation, media space of city, media war and terrorism in media, connection between narrative, visuality and media; specific attention is paid to analysis of the last innovations in area of computer game and their influence on everyday life.
\end{abstract}

Keywords: media environment; archive; media reality; media war; media subject; computer games; narrative. 